\title{
Effect of antihypertensive therapy on endothelial markers in newly diagnosed Stage 1 hypertension: a randomized single-centre study
}

\author{
Mehmet Ali Nahit Şendur, Gülay Sain Güven*, Hikmet Yorgun**, Ahmet Hakan Ateş ${ }^{1}$, Uğur Canpolat ${ }^{2}$, \\ Hamza Sunman³, Sevilay Karahan***, Barış Kaya**, Kudret Aytemir**
}

Clinic of Medical Oncology, Ankara Numune Training and Research Hospital; Ankara-Turkey

Departments of *Internal Medicine, ${ }^{* *}$ Cardiology, and ${ }^{* * *}$ Biostatistics, Faculty of Medicine, Hacettepe University; Ankara-Turkey

${ }^{1}$ Clinic of Cardiology, Samsun Training and Research Hospital; Samsun-Turkey

${ }^{2}$ Clinic of Cardiology, Türkiye Yüksek İhtisas Training and Research Hospital; Ankara-Turkey

${ }^{3}$ Clinic of Cardiology, Dışkapı Yıldırım Beyazıt Training and Research Hospital; Ankara-Turkey

\section{ABSTRACT}

Objective: This study was aimed to investigate the effects of olmesartan or nebivolol treatment on blood pressure and some endothelial function markers in newly diagnosed patients with stage 1 essential hypertension.

Methods: This randomized open label study included 85 newly diagnosed patients with stage 1 hypertension ( 50 males, mean age: $52 \pm 9$ years). Blood pressure, flow mediated vasodilatation (FMD) and echocardiographic measurements of the patients were taken before and 8 weeks after the beginning of treatment with olmesartan or nebivolol. Nitric oxide, plasminogen activator inhibitor 1 (PAI-1) and C reactive protein (CRP) levels measured in serum samples before and after treatment, were compared. Basal variables that can affect the antihypertensive response were evaluated by multivariate logistic regression analysis.

Results: The reduction observed in the systolic and diastolic blood pressures after antihypertensive treatment was significant ( $p<0.05)$. FMD was significantly improved after treatment in both nebivolol and olmesartan groups; however, there was no significant difference between nebivolol and olmesartan groups ( $p=0.6$ ). While CRP and PAI-1 levels decreased, nitric oxide levels increased in both nebivolol and olmesartan treatment groups; but these changes were not statistically significant. No drug related complication was observed.

Conclusion: This study has indicated that olmesartan and nebivolol causes similar changes in blood pressure response, FMD and endothelial function biomarkers improved. These results suggest that antihypertensive treatment, independent of the medication used, is associated with endothelial function improvement. (Anadolu Kardiyol Derg 2014; 14: 363-9)

Key words: flow mediated vasodilatation, endothelial biomarkers, antihypertensive treatment

\section{Introduction}

The endothelium has an important role in the maintenance of vascular structure and tone owing to its roles in coagulationfibrinolysis system, platelet aggregation and vascular smooth muscle cell proliferation $(1,2)$. It has been reported in numerous studies that endothelin, which is one of the vasoconstrictor molecules secreted from endothelium, is increased in both hypertensive and pre-hypertensive patients and is associated with a proinflammatory and prothrombotic state (3). Contrarily, nitric oxide, one of the vasodilator agents secreted from endothelium, is a strong vasodilator with a short half-life, and inhibits platelet aggregation and adhesion, vascular smooth muscle cell proliferation and migration $(4,5)$.

Assessment of endothelial functions is important as it is an indicator of atherosclerosis (6). Measurement of flow-mediated vasodilation (FMD) of the brachial artery is one of the methods most commonly used in assessing endothelial functions. Nitric oxide (NO) is the most important molecule among those that enable this vasodilation (1). Therefore, in endothelial dysfunction, along with the impairment in vascular structure and tone, decreased endothelial NO leads to a decrease in anti-inflammatory and antithrombotic effects; thereby, a prothrombotic state is induced (7). Additionally, 'plasminogen activator inhibitor-1' (PAI-1), which is secreted from the endothelium, impairs the balance between normal haemostasis and fibrinolysis and thus contributes to the prothrombotic state (8).

The relation between hypertension and endothelial dysfunction has been demonstrated in many studies $(9,10)$. Besides, effective treatment of hypertension both prevents the occurrence of atherosclerotic diseases and causes improvement in endothelial functions $(11,12)$. Previous studies have found that the drugs that block the renin-angiotensin system had a higher

Address for Correspondence: Dr. Mehmet Ali Nahit Şendur, Ankara Numune Eğitim ve Araştırma Hastanesi, 
effect on FMD compared to the other antihypertensive drugs $(13,14)$. However, third generation beta blockers in particular also possess vasodilator properties. The present study investigated the effects of olmesartan, which is frequently used in antihypertensive therapy, and nebivolol, which has NO-dependent vasodilator properties, on FMD and endothelial function markers.

\section{Methods}

\section{Study group}

Patients $\geq 18$ years who presented to the outpatient clinics of Internal Medicine Units of the Department of Internal Medicine, between May 2009 and March 2010 and newly diagnosed with stage 1 essential hypertension according to the recently published guidelines of the European Society of Cardiology formed the patient group of this randomized, open-ended study (15). Patients, who had been receiving drugs with antihypertensive effects for various reasons and had a blood pressure $\geq 160 / 100$ $\mathrm{mm} \mathrm{Hg}$, those who had to receive combination therapy according to the current guidelines, and those who had been receiving or had to receive statins or antidiabetic therapy at the time of admission, were not included in the study. Since renal or hepatic dysfunction are likely to influence drug distribution and metabolism and thus the response to antihypertensive therapy, patients with elevated hepatic transaminase levels (greater than 3 folds) and elevated creatinine levels (>1.5 mg/dL) were also excluded from the study In addition, pregnant women, patients receiving non-steroidal anti-inflammatory drugs, those with a body mass index (BMI) $>35 \mathrm{~kg} / \mathrm{m}^{2}$, those with hypothyroidism, hyperthyroidism, systemic inflammatory disease and neoplastic diseases, or those with a history of coronary artery disease or peripheral artery disease were not included in the study. Patients included in the study were randomized to olmesartan or nebivolol groups in the order of admission to the outpatient clinic. Blood pressure response and alterations in endothelial functions were considered as the primary end points of the study. Informed consents were obtained from the patients and the study was approved by the local ethics committee (FON 09/39-40).

\section{Measurements and examinations}

\section{Blood pressure}

In accordance with the recommendations of the current guidelines for hypertension, blood pressure measurement was performed in both arms for at least 2 times at 5 -minute intervals and the mean of two measurements was calculated (15). Patients with a blood pressure of $140 / 90 \mathrm{~mm} \mathrm{Hg}$ and higher were invited for a control blood pressure measurement one week later and were evaluated in the same way for the second time. Blood pressures of all patients were measured by the same person using a mercury sphygmomanometer.

\section{Echocardiography}

Echocardiographic images were obtained via GE Vivid 5 (General Electric, Vingmed, System Five, Horten, Norway) ultrasound machine using a $3.75 \mathrm{MHz}$ standard probe in accordance with the guidelines of "American Society of Echocardiography" (16). Posterior wall thickness (PWT), interventricular septum thickness (IVST), left ventricular end-systolic diameter (LVESD) and left ventricular end-diastolic diameter (LVEDD) were measured in all patients. As was recommended by the American Society of Echocardiography, left ventricular mass (LVM) was calculated according to the Devereux method (17). Accordingly, $L V M=1.04$ [(IVST+LVEDD+PWT) ${ }^{3}-\left(\right.$ LVEDD) ${ }^{3}$ ]-13.6 (gr). "Left ventricular mass index" (LVMI) was calculated dividing LVM by body surface area.

\section{Flow-mediated vasodilation}

In the present study, FMD was measured by B-Mode Ultrasound using a $7.5 \mathrm{MHz}$ vertical vascular transducer (General Electric, Vingmed, System Five, Horten, Norway) and the diameter of the brachial artery and flow rate using a pulsed Doppler signal at an angle $70^{\circ}$ to the artery, were measured (18). After brachial artery was identified at the antecubital fossa in the longitudinal plane and after appropriate transducer position was provided, this area was marked and the arm was kept in the same position throughout the study. An appropriate size sphygmomanometer cuff was placed $2 \mathrm{~cm}$ proximal to the antecubital fossa and inflated to $50 \mathrm{~mm} \mathrm{Hg}$ over the systolic blood pressure (SBP) and kept inflated for 5 minutes. Then the cuff was rapidly inflated and at the $60^{\text {th }}$ second of reactive hyperaemia observed following deflation of the cuff FMD was obtained by measuring the diameter of the brachial artery and by calculating the percentage of change in baseline diameter. For obtaining standardized images, arterial diameter was measured at a fixed distance from an anatomical marker. The distance from the anterior to the posterior interface between the media and adventitia ( $M$ line) was measured under continuous ECG monitoring synchronized with the $R$ wave peaks at the end of diastole. For each study, the mean diameter was calculated from four cardiac cycles. Brachial artery dilatation in response to reactive hyperaemia was expressed as the percent change in the diameter before the cuff was inflated.

\section{Endothelial markers}

Samples obtained from the patients before and after treatment were centrifuged at $4^{\circ} \mathrm{C}$ for 10 minutes in the 'Nuve nf $800 \mathrm{r}$ Centrifuge' branded device. The serum samples were transferred into eppendorf tubes and kept at $-80^{\circ} \mathrm{C}$ until the time of analysis. After all samples were collected, they were analysed at the laboratories of the Biochemistry Department. Nitric oxide (nitrite+nitrate) and PAI-1 values were obtained after preparing the standards for Elisa. $C$ reactive protein (CRP) levels were measured by rate nephelometry (IMAGE, Backman, USA) method. 


\section{Follow-up}

The patients with newly diagnosed stage 1 hypertension were assigned to olmesartan or nebivolol groups as a single antihypertensive agent. After the patients were informed about compliance with therapy, they were invited for control examinations on the $8^{\text {th }}$ week by phone. In addition to blood pressure measurement, endothelial biomarker and FMD measurements were repeated. No drug-related adverse event was observed.

\section{Statistical analysis}

Statistical analysis was performed using the SPSS for Windows 15.0 program (SPSS, Chicago, IL). Numerical variables were presented as mean \pm standard deviation, whereas categorical variables were presented as number and percentage. Baseline characteristics of the antihypertensive therapy groups were compared by t-test or Chi-square test. Variables were analysed by Shapiro-Wilk test and it was determined that variables showed normal distribution. Therefore, changes between the pre-treatment and post-treatment were analysed by repeated measures analysis of variance in both groups. The level of significance was set at $=0.05$. Baseline variables that could affect antihypertensive response were analysed by multiple logistic regression analysis. Endothelial function assessment was done by the same researcher at every assessment and intraobserver variability for the repeated measurements of the resting diameter was found to be $0.1 \pm 0.06 \mathrm{~mm}$.

\section{Results}

A total of 85 patients were analysed out of 96 patients, since 6 of the patients did not attend the control visits, and 2 patients were diagnosed with coronary artery disease, 2 of them with hyperparathyroidism and 1 patient with lung cancer during follow-up. Forty two of 85 patients received olmesartan and the remaining 43 patients received nebivolol. Females accounted for $54.8 \%$ of the patients receiving olmesartan therapy and $74.4 \%$ of the patients receiving nebivolol therapy $(p=0.095)$. Whilst the mean age was $54.9 \pm 7.9$ years in the olmesartan group, it was $50.1 \pm 9.4$ years in the nebivolol group $(p=0.013)$. No statistically significant difference was determined between the groups receiving antihypertensive therapy in terms of prevalence of smoking, presence of family history of coronary artery disease, and prevalence of metabolic syndrome. Moreover, baseline total cholesterol, triglyceride, LDL, HDL, and fasting plasma glucose levels of the patients receiving antihypertensive therapy were similar in both groups (Table 1). In addition, no significant difference was found between the pre-treatment echocardiography findings of the patients receiving olmesartan or nebivolol therapy in terms of left ventricular systolic functions and left ventricular mass indexes.

None of the patients receiving olmesartan therapy showed impairment in liver function tests. Symptomatic bradycardia was not observed in the patients receiving nebivolol therapy. The
Table 1. Baseline demographic and clinical characteristics of the cases

\begin{tabular}{|c|c|c|c|c|}
\hline \multirow{2}{*}{\multicolumn{2}{|c|}{$\begin{array}{l}\text { Age, mean } \pm \text { Std } \\
\text { deviation }\end{array}$}} & Olmesartan ( $n=42$ ) & Nebivolol $(n=43)$ & $\boldsymbol{P}$ \\
\hline & & $54.9 \pm 7.9$ & $50.1 \pm 9.4$ & 0.013 \\
\hline \multicolumn{2}{|c|}{$\begin{array}{l}\text { Gender, female } \\
\text { /male }\end{array}$} & $23 / 19(54.8 / 45.2)$ & $32 / 11(74.4 / 25.6)$ & 0.095 \\
\hline \multirow[t]{3}{*}{ Smoking } & $\begin{array}{l}\text { Never } \\
\text { smoked }\end{array}$ & $22(52.4)$ & $28(65.1)$ & \multirow{3}{*}{0.268} \\
\hline & Quitted & $9(21.4)$ & $4(9.3)$ & \\
\hline & $\begin{array}{l}\text { Current } \\
\text { smoker }\end{array}$ & $11(26.2)$ & $11(25.6)$ & \\
\hline \multicolumn{2}{|c|}{$\begin{array}{l}\text { Family history of } \\
\text { CAD, no/yes }\end{array}$} & $31 / 11(73.8 / 26.2)$ & $32 / 11(74.4 / 25.6)$ & 0.949 \\
\hline \multicolumn{2}{|c|}{$\begin{array}{l}\text { Metabolic } \\
\text { syndrome, no/yes }\end{array}$} & $18 / 24(42.9 / 52.1)$ & $19 / 24(44.2 / 55.8)$ & 0.902 \\
\hline \multicolumn{2}{|c|}{$\begin{array}{l}\text { Total cholesterol, } \\
\mathrm{mg} / \mathrm{dL}\end{array}$} & $203.9 \pm 36.3$ & $202.0 \pm 38.2$ & 0.810 \\
\hline \multicolumn{2}{|c|}{ Triglyceride, $\mathrm{mg} / \mathrm{dL}$} & $134.2 \pm 52.5$ & $143.2 \pm 57.8$ & 0.456 \\
\hline \multicolumn{2}{|c|}{$\mathrm{LDL}, \mathrm{mg} / \mathrm{dL}$} & $130.0 \pm 29.9$ & $122.8 \pm 28.3$ & 0.260 \\
\hline \multicolumn{2}{|c|}{$\mathrm{HDL}, \mathrm{mg} / \mathrm{dL}$} & $52.4 \pm 11.6$ & $56.6 \pm 13.8$ & 0.136 \\
\hline \multicolumn{2}{|c|}{$\begin{array}{l}\text { Fasting plasma } \\
\text { glucose, } \mathrm{mg} / \mathrm{dL}\end{array}$} & $95.2 \pm 10.5$ & $93.6 \pm 11.0$ & 0.084 \\
\hline \multirow{2}{*}{\multicolumn{2}{|c|}{$\mathrm{BMI}, \mathrm{kg} / \mathrm{m}^{2}$}} & Olmesartan $(n=42)$ & $30.6 \pm 3.8$ & $30.6 \pm 3.9$ \\
\hline & & Nebivolol ( $n=43)$ & $30.4 \pm 4.7$ & $30.4 \pm 4.6$ \\
\hline \multirow{2}{*}{\multicolumn{2}{|c|}{$\begin{array}{l}\text { Waist } \\
\text { circumference, cm }\end{array}$}} & Olmesartan $(n=42)$ & $104.1 \pm 10.9$ & $104.1 \pm 11.0$ \\
\hline & & Nebivolol ( $n=43)$ & $101.0 \pm 12.5$ & $100.9 \pm 12.2$ \\
\hline
\end{tabular}

BMI - body mass index; CAD - coronary artery disease; HDL - high density lipoprotein; LDL - low density lipoprotein

mean creatinine level increased from $0.82 \pm 0.19 \mathrm{mg} / \mathrm{dL}$ before treatment to $0.83 \pm 0.18 \mathrm{mg} / \mathrm{dL}$ after treatment in patients receiving olmesartan therapy; whereas, it increased to $0.75 \pm 0.14 \mathrm{mg} /$ $\mathrm{dL}$ after treatment from $0.74 \pm 0.16 \mathrm{mg} / \mathrm{dL}$ before treatment ( $p>0.05$ ) in patients receiving nebivolol therapy. The change was not statistically significant in either group.

\section{Blood pressure}

Pre-treatment SBP was $154.2 \pm 4.0 \mathrm{~mm} \mathrm{Hg}$ in patients receiving olmesartan therapy and $151.2 \pm 4.1 \mathrm{~mm} \mathrm{Hg}$ in patients receiving nebivolol therapy; whereas, post-treatment SBP was $131.4 \pm 11.8 \mathrm{~mm} \mathrm{Hg}$ in patients receiving olmesartan therapy and $132.3 \pm 9.6 \mathrm{~mm} \mathrm{Hg}$ in patients receiving nebivolol therapy. While the decrease in SBP was statistically significant in each treatment group, no significant difference was found between the groups ( $p=0.452$ ) (Fig. 1). The mean age of the patients in the olmesartan group was found to be higher than that of the patients in the nebivolol group $(p=0.013)$. Antihypertensive response according to age was assessed by multiple logistic regression analysis. No significant difference was found between the groups when adjusted according to the age $(p=0.516)$. Pre-treatment DBPs were $94.9 \pm 2.4 \mathrm{~mm} \mathrm{Hg}$ and 
$93.9 \pm 2.5 \mathrm{~mm} \mathrm{Hg}$, in patients receiving olmesartan and nebivolol therapy, respectively; whereas post-treatment DBP was $83.2 \pm 2.4$ $\mathrm{mm} \mathrm{Hg}$ in the patients receiving olmesartan therapy and $84.8 \pm 6.4$ $\mathrm{mm} \mathrm{Hg}$ in the patients receiving nebivolol therapy. Although the decrease in diastolic blood pressure was statistically significant in each group, no significant difference was found between the groups $(\mathrm{p}=0.752)$.

\section{Flow-mediated vasodilation}

Pre-treatment and post-treatment brachial artery diameters were similar ( $p=0.887$ and $p=0.584$ respectively) in patients receiving olmesartan therapy and nebivolol therapy. With regard to percent change in FMD, it was observed that FMD increased to $8.0 \pm 2.5 \%$ from $5.5 \pm 2.1 \%$ in patients receiving olmesartan therapy $(p<0.001)$ and to $8.1 \pm 2.7 \%$ from $5.9 \pm 2.1 \%$ in patients receiving nebivolol therapy $(p<0.001)$ (Table 2). The change in either group was similar with no statistical difference between the groups $(p=0.6)$.

\section{Endothelial markers}

The pre-treatment and post-treatment endothelial marker levels in the olmesartan and nebivolol groups are demonstrated in Table 3. While there was a decrease in CRP and PAI-1 levels and an increase in nitric oxide values in both treatment groups, no significant result was obtained (Table 3).

\section{Discussion}

As far as we know, the present study is the first study that investigates the antihypertensive efficacy of nebivolol, which has highly selective vasodilator effects, and olmesartan, which is an angiotensin receptor blocker, and their effects on endothe-

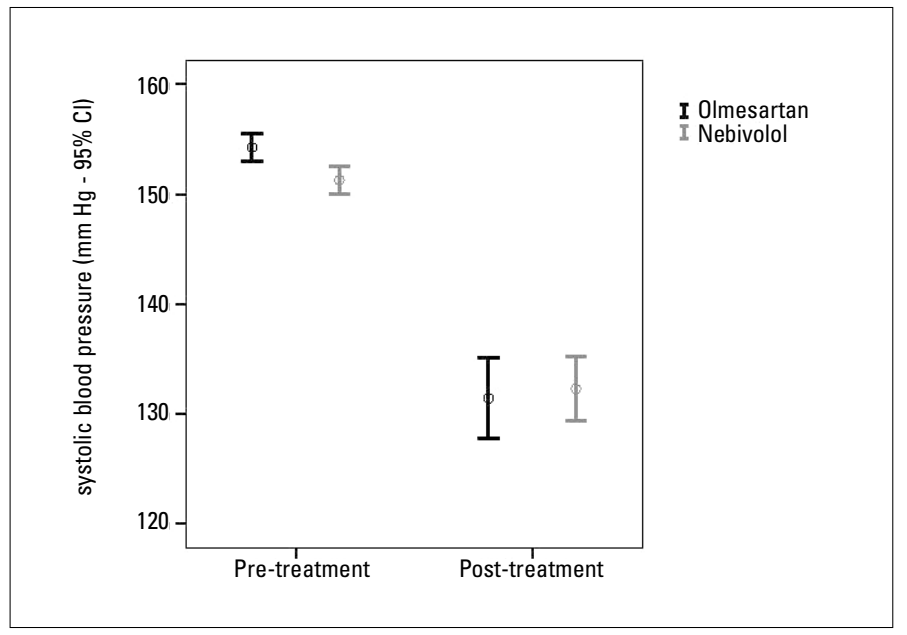

Figure 1. The changes in systolic blood pressure levels after treatment in patients receiving olmesartan or nebivolol therapy

Table 2. The changes in brachial artery diameter and flow-mediated vasodilation (FMD) values with olmesartan and nebivolol therapies

\begin{tabular}{|c|c|c|c|c|c|c|c|}
\hline Variable & Drug & Before treatment & After treatment & Time & Group & Time group & Intragroup \\
\hline \multirow[t]{2}{*}{ Brachial artery diameter, $\mathrm{mm}$} & Olmesartan $(n=42)$ & $3.6 \pm 0.47$ & $3.61 \pm 0.46$ & $F=6.225$ & $F=0.070$ & $F=0.387$ & $\begin{array}{l}F=1.733 \\
P=0.192\end{array}$ \\
\hline & Nebivolol ( $n=43)$ & $3.6 \pm 0.47$ & $3.66 \pm 0.53$ & $P=0.015$ & $P=0.792$ & $P=0.535$ & $\begin{array}{l}F=4.917 \\
P=0.029\end{array}$ \\
\hline \multirow[t]{2}{*}{ FMD, \% } & Olmesartan $(n=42)$ & $5.5 \pm 2.1$ & $8.0 \pm 2.5$ & $F=104.797$ & $F=0.277$ & $F=0.461$ & $\begin{array}{c}\mathrm{F}=58.885 \\
P<0.001\end{array}$ \\
\hline & Nebivolol ( $n=43)$ & $5.9 \pm 2.1$ & $8.1 \pm 2.7$ & $P<0.001$ & $P=0.600$ & $P=0.499$ & $\begin{array}{c}\mathrm{F}=46.224 \\
p<0.001\end{array}$ \\
\hline
\end{tabular}

Table 3. The changes in endothelial markers with olmesartan and nebivolol therapies

\begin{tabular}{|c|c|c|c|c|c|c|c|}
\hline & & Before treatment & After treatment & Time $P$ & Group $P$ & Time group $\boldsymbol{P}$ & Intragroup $P$ \\
\hline \multirow{2}{*}{$\mathrm{CRP}, \mathrm{mg} / \mathrm{dL}$} & Olmesartan $(n=42)$ & $0.70 \pm 0.73$ & $0.49 \pm 0.37$ & \multirow{2}{*}{$\begin{array}{l}\mathrm{F}=8.557 \\
P=0.004\end{array}$} & \multirow{2}{*}{$\begin{array}{l}F=5.240 \\
P=0.025\end{array}$} & \multirow{2}{*}{$\begin{array}{l}F=5.105 \\
P=0.026\end{array}$} & $\begin{array}{c}\mathrm{F}=13.284 \\
p<0.001\end{array}$ \\
\hline & Nebivolol $(n=43)$ & $0.41 \pm 0.22$ & $0.39 \pm 0.22$ & & & & $\begin{array}{l}F=0.224 \\
P=0.637\end{array}$ \\
\hline \multirow[t]{2}{*}{ Nitrite + Nitrate total $(\mu \mathrm{M})$} & Olmesartan $(n=42)$ & $11.7 \pm 3.8$ & $13.3 \pm 8.3$ & \multirow{2}{*}{$\begin{array}{l}\mathrm{F}<0.001 \\
P=0.984\end{array}$} & \multirow{2}{*}{$\begin{array}{l}F=0.930 \\
P=0.338\end{array}$} & \multirow{2}{*}{$\begin{array}{l}F=2.356 \\
P=0.129\end{array}$} & $\begin{array}{l}F=1.135 \\
P=0.290\end{array}$ \\
\hline & Nebivolol $(n=43)$ & $14.5 \pm 9.2$ & $12.9 \pm 6.2$ & & & & $\begin{array}{l}F=1.223 \\
P=0.272\end{array}$ \\
\hline \multirow[t]{2}{*}{ PAI-1, pg/mL } & Olmesartan $(n=42)$ & $3682.0 \pm 837.1$ & $3511.4 \pm 1101.3$ & \multirow{2}{*}{$\begin{array}{l}F=3.019 \\
P=0.086\end{array}$} & \multirow{2}{*}{$\begin{array}{l}\mathrm{F}=0.496 \\
P=0.483\end{array}$} & \multirow{2}{*}{$\begin{array}{l}\mathrm{F}=0.230 \\
P=0.633\end{array}$} & $\begin{array}{l}F=0.782 \\
P=0.379\end{array}$ \\
\hline & Nebivolol $(n=43)$ & $3617.4 \pm 1140.9$ & $3316.7 \pm 1104.9$ & & & & $\begin{array}{l}F=2.488 \\
P=0.119\end{array}$ \\
\hline
\end{tabular}


lial function markers. According to the results of this study, the decrease in systolic and diastolic blood pressure (DBP), the increase in FMD and the changes in endothelial markers were similar both in patients receiving olmesartan and in those receiving nebivolol.

In the 2007 Guidelines for the Management of Arterial Hypertension and the 2009 Reappraisal of European guidelines on hypertension management of the European Society of Cardiology and European Society of Hypertension, it has been stated that all antihypertensive medications cause similar reduction in blood pressure and there is no difference between the groups (15). However, numerous studies comparing the efficacy of antihypertensive drugs have been conducted. Stumpe et al. (19) in their study on patients with mild-moderate hypertension, found that blood pressure response was similar with atenolol and olmesartan therapy at the end of 104 weeks; whilst the decrease in mean SBP was $24.6 \mathrm{~mm} \mathrm{Hg}$ and the decrease in mean DBP was $15.2 \mathrm{~mm} \mathrm{Hg}$ at the end of 104 weeks in patients receiving olmesartan therapy, the decrease in mean SBP was $21.5 \mathrm{~mm} \mathrm{Hg}$ and the decrease in mean DBP was $13.8 \mathrm{~mm} \mathrm{Hg}$ in patients receiving atenolol therapy. Van Nueten et al. (20), who investigated the effects of nebivolol and enalapril, an angiotensin converting enzyme inhibitor, on blood pressure response, gave $5 \mathrm{mg}$ of nebivolol or $10 \mathrm{mg}$ of enalapril to patients with mildmoderate hypertension; whilst the decrease in mean SBP was $14 \mathrm{~mm} \mathrm{Hg}$ and the decrease in mean DBP was $12.3 \mathrm{~mm} \mathrm{Hg}$ at the end of 3-months treatment period in patients receiving nebivolol therapy, the decrease in mean SBP was $13 \mathrm{~mm} \mathrm{Hg}$ and the decrease in mean DBP was $9.9 \mathrm{~mm} \mathrm{Hg}$ in patients receiving enalapril therapy. In the present study, nebivolol, a new generation beta blocker, was compared with olmesartan and SBP/DBP decreased by $22.8 / 11.7 \mathrm{~mm} \mathrm{Hg}$ at the end of 8 weeks in patients receiving olmesartan therapy, whereas a decrease of 19.8/10.7 $\mathrm{mm} \mathrm{Hg}$ was observed in patients receiving nebivolol therapy.

Unfavourable effects of hypertension on endothelial function has been known for a long time (21). Previous studies have demonstrated that cardiovascular risk factors including hypertension impair endothelial functions by initiating oxidative stress and pro-inflammatory process and decrease NO synthesis, which enables vasodilation $(22,23)$. In the present study, besides the blood pressure lowering effects of antihypertensive drugs, their effects on endothelial functions have been assessed by flow-mediated vasodilation method. In the present study, while a statistically significant increase was observed in FMD in the nebivolol and olmesartan therapy groups at the end of 8 weeks, the change in the treatment groups was similar. Lekakis et al. (24) investigated the effects of nebivolol, one of the new generation beta blockers, on FMD in patients with a history of coronary artery disease. $0 \mathrm{n}$ the $4^{\text {th }}$ week of nebivolol and atenolol treatments, they observed a significant increase in FMD in patients receiving nebivolol; however, this effect was not observed in patients receiving atenolol; and they stated that this effect of nebivolol might be nitric oxide-mediated. In another study that used telmisartan, an angiotensin receptor blocker, a significant increase was observed in 8-weeks FMD values versus pretreatment values in patients with SBP/DBP $<180 / 100 \mathrm{~mm} \mathrm{Hg}$ (25). Perrone-Flardi et al. (26) in patients with hypertension or coronary artery disease receiving beta blockers added candesartan or placebo to the treatment; while no change was observed in the blood pressure of patients that received additional candesartan at the end of 2 months, a significant increase was observed in FMD as compared to placebo. The results of this study demonstrate that both new generation beta blockers and angiotensin receptor blockers have favourable effects on FMD.

Tarighi et al. (27) conducted a study in 35 patients with mildmoderate hypertension and investigated the effects of nebivolol therapy on prothrombotic markers and observed a statistically significant decrease in tPA and fibrinogen levels on the $2^{\text {nd }}$ month, whereas a non-significant decrease was observed in PAI-1 levels. Erdem et al. (28) stated that the effects of angiotensin converting enzyme inhibitors on fibrinolytic system might occur via angiotensin II blockade. Remkova et al. (29) investigated the effects of telmisartan or perindopril therapies on prothrombotic state in hypertensive patients; whilst a decrease was observed in PAI-1 levels and other thrombotic markers at the end of the $1^{\text {st }}$ month in patients receiving perindopril, no significant change was observed in PAI-1 levels in patients receiving telmisartan therapy although a decrease was observed in fibrinogen levels. In the present study, a decrease was observed in CRP and PAI- 1 levels at the end of $8^{\text {th }}$ week in both treatment groups, whereas an increase was determined in nitrite and nitrate levels, which are NO products. It has been suggested that endothelial dysfunction in hypertensive patients results from decreased synthesis of molecules such as NO that is secreted from the endothelium and cause vasodilation, decreased vascular smooth muscle cell response to these molecules, increased secretion of vasoconstrictor molecules, and activation of renin-angiotensin-aldosterone system (1, 2). It has been propounded that angiotensin receptor blockers improve endothelial functions by decreasing vasoconstriction due to binding to angiotensin II type 1 receptors, as well as binding to the type 2 receptors that enhance NO synthesis $(30,31)$. Beta blockers have been reported to improve endothelial function markers by decreasing reactive oxygen molecules; but, nebivolol in particular, improves endothelial functions by enhancing NO synthesis (32). In the present study, improvement was observed in endothelial markers in both treatment groups with no significant intergroup or intragroup difference. In studies, the changes in endothelial biomarkers may seem to be prominent because of short follow-up period; therefore, it is thought that the precise effects of these drugs on endothelial markers might not have completely developed in this study.

\section{Study limitations}

One of the major limitations of this study is the limited number of study population. In addition, BMI of the study participants was 
approximately $30 \mathrm{~kg} / \mathrm{m}^{2}$, thereby the results of the present study cannot be generalized to all hypertensive patients. Moreover, flow rate was not assessed during FMD measurements. Another limitation is the fact that assessment of adherence to therapy relied on self-reported history of the patients. However, the study is important as being the first study that compared the effects of olmesartan, an angiotensin receptor blocker, and nebivolol, a highly-selective beta blocker. Although the number of cases was small, the study included higher number of cases than the clinical studies with published results, among the studies that investigated endothelial functions and numerous parameters. We think that the present study will illuminate detailed clinical studies that would strengthen the evidence on this subject.

\section{Conclusion}

In conclusion, in the present study that investigated the effects of olmesartan and nebivolol therapies on blood pressure response and endothelial markers in newly diagnosed stage 1 hypertensive patients, an improvement was observed both in FMD and endothelial function markers in addition to blood pressure response at the end of 8 weeks and these results were found to be similar in both groups. Large-scale studies are needed on the clinical outcomes of the effects of antihypertensive drugs on endothelial biomarkers or prothrombotic markers in addition to their blood pressure-lowering effects.

Conflict of interest: None declared.

Peer-review: Externally peer-reviewed.

Authorship contributions: Concept - M.A.N.Ş., K.A.; Design U.C.; Supervision - H.Y., A.H.A.; Resource - G.S.G.; Materials H.S.; Data collection \&/or processing - M.A.N.Ş., H.Y., A.A.; Analysis \&/or interpretation - U.C., H.Y., S.K.; Literature search M.A.N.Ş., H.Y.; Writing - M.A.N.Ş., H.Y.; Critical review - G.S.G., K.A.; Other - B.K.

\section{References}

1. Deanfield JE, Halcox JP, Rabelink TJ. Endothelial function and dysfunction: testing and clinical relevance. Circulation 2007; 115: 1285-95.

2. Landmesser $\mathrm{U}$, Drexler $\mathrm{H}$. Endothelial function and hypertension. Curr Opin Cardiol 2007; 22: 316-20. [CrossRef]

3. Jagroop IA, Daskalopoulou SS, Mikhailidis DP. Endothelin-1 and human platelets. Curr Vasc Pharmacol 2005; 3: 393-9. [CrossRef]

4. Tschudi MR, Criscione L, Novosel D, Pfeiffer K, Luscher TF. Antihypertensive therapy augments endothelium-dependent relaxations in coronary arteries of spontaneously hypertensive rats. Circulation 1994; 89: 2212-8. [CrossRef]

5. Silva BR, Pernomian L, Bendhack LM. Contribution of oxidative stress to endothelial dysfunction in hypertension. Front Physiol 2012; 3: 441. [CrossRef]
6. Modena MG, Bonetti L, Coppi F, Bursi F, Rossi R. Prognostic role of reversible endothelial dysfunction in hypertensive postmenopausal women. J Am Coll Cardiol 2002; 40: 505-10. [CrossRef]

7. Gamboa A, Shibao C, Diedrich A, Choi L, Pohar B, Jordan J, et al. Contribution of endothelial nitric oxide to blood pressure in humans. Hypertension 2007; 49: 170-7. [CrossRef]

8. Thogersen AM, Jansson JH, Boman K, Nilsson TK, Weinehall L, Huhtasaari $F$, et al. High plasminogen activator inhibitor and tissue plasminogen activator levels in plasma precede a first acute myocardial infarction in both men and women: evidence for the fibrinolytic system as an independent primary risk factor. Circulation 1998; 98: 2241-7. [CrossRef]

9. Juonala M, Viikari JS, Laitinen T, Marniemi J, Helenius H, Ronnemaa $T$, et al. Interrelations between brachial endothelial function and carotid intima-media thickness in young adults: the cardiovascular risk in young Finns study. Circulation 2004; 110: 2918-23. [CrossRef]

10. Iwamoto Y, Maruhashi T, Fujii Y, Idei N, Fujimura N, Mikami S, et al. Intima-media thickness of brachial artery, vascular function, and cardiovascular risk factors. Arterioscler Thromb Vasc Biol 2009; 32: 2295-303. [CrossRef]

11. Lenfant $C$, Chobanian AV, Jones DW, Roccella EJ. Seventh report of the Joint National Committee on the Prevention, Detection, Evaluation, and Treatment of High Blood Pressure (JNC 7): resetting the hypertension sails. Hypertension 2003; 41: 1178-9. [CrossRef]

12. Dorresteijn JA, Schrover IM, Visseren FL, Scheffer PG, Oey PL, Danser $A H$, et al. Differential effects of renin-angiotensinaldosterone system inhibition, sympathoinhibition and diuretic therapy on endothelial function and blood pressure in obesityrelated hypertension: a double-blind, placebo-controlled crossover trial. J Hypertens 2012; 31: 393-403. [CrossRef]

13. Koh KK, Han SH, Chung WJ, Ahn JY, Jin DK, Kim HS, et al. Comparison of effects of losartan, irbesartan, and candesartan on flow-mediated brachial artery dilation and on inflammatory and thrombolytic markers in patients with systemic hypertension. Am J Cardiol 2004; 93: 1432-5. [CrossRef]

14. Morimoto S, Yano Y, Maki K, Sawada K. Renal and vascular protective effects of telmisartan in patients with essential hypertension. Hypertens Res 2006; 29: 567-72. [CrossRef]

15. Mancia G, De Backer G, Dominiczak A, Cifkova R, Fagard R, Germano $G$, et al. 2007 Guidelines for the management of arterial hypertension: The Task Force for the Management of Arterial Hypertension of the European Society of Hypertension (ESH) and of the European Society of Cardiology (ESC). Eur Heart J 2007; 28: 1462-536.

16. Douglas PS, DeCara JM, Devereux RB, Duckworth S, Gardin JM, Jaber WA, et al. Echocardiographic imaging in clinical trials: American Society of Echocardiography Standards for echocardiography core laboratories: endorsed by the American College of Cardiology Foundation. J Am Soc Echocardiogr 2009; 22 : 755-65. [CrossRef]

17. Devereux RB, Reichek N. Echocardiographic determination of left ventricular mass in man. Anatomic validation of the method. Circulation 1977; 55: 613-8. [CrossRef]

18. Celermajer DS, Sorensen KE, Bull C, Robinson J, Deanfield JE. Endothelium-dependent dilation in the systemic arteries of asymptomatic subjects relates to coronary risk factors and their interaction. J Am Coll Cardiol 1994; 24: 1468-74. [CrossRef]

19. Stumpe KO, Agabiti-Rosei E, Zielinski T, Schremmer D, Scholze J, Laeis $\mathrm{P}$, et al. Carotid intima-media thickness and plaque volume 
changes following 2-year angiotensin II-receptor blockade. The Multicentre Olmesartan atherosclerosis Regression Evaluation (MORE) study. Ther Adv Cardiovasc Dis 2007; 1: 97-106. [CrossRef]

20. Van Nueten L, Schelling A, Vertommen C, Dupont AG, Robertson Jl. Nebivolol vs. enalapril in the treatment of essential hypertension: a doubleblind randomised trial. J Hum Hypertens 1997; 11: 813-9. [CrossRef]

21. Benjamin EJ, Larson MG, Keyes MJ, Mitchell GF, Vasan RS, Keaney JF Jr, et al. Clinical correlates and heritability of flow-mediated dilation in the community: the Framingham Heart Study. Circulation 2004; 109: 613-9. [CrossRef]

22. Wallace SM, Yasmin, McEniery CM, Maki-Petaja KM, Booth AD, Cockcroft JR, et al. Isolated systolic hypertension is characterized by increased aortic stiffness and endothelial dysfunction. Hypertension 2007; 50: 228-33. [CrossRef]

23. Panza JA, Quyyumi AA, Brush JE Jr, Epstein SE. Abnormal endothelium-dependent vascular relaxation in patients with essential hypertension. N Engl J Med 1990; 323: 22-7. [CrossRef]

24. Lekakis JP, Protogerou A, Papamichael C, Vamvakou G, Ikonomidis I, Fici $F$, et al. Effect of nebivolol and atenolol on brachial artery flow-mediated vasodilation in patients with coronary artery disease. Cardiovasc Drugs Ther 2005; 19: 277-81. [CrossRef]

25. Jung AD, Kim W, Park SH, Park JS, Cho SC, Hong SB, et al. The effect of telmisartan on endothelial function and arterial stiffness in patients with essential hypertension. Korean Circ J 2009; 39: 180-4. [CrossRef]
26. Perrone-Filardi P, Corrado L, Brevetti G, Silvestro A, Dellegrottaglie S, Cafiero $M$, et al. Effects of AT1 receptor antagonism with candesartan on endothelial function in patients with hypertension and coronary artery disease. J Clin Hypertens (Greenwich) 2009; 11: 260-5. [CrossRef]

27. Tarighi B, Kurum T, Demir M, Azcan SN. The effects of nebivolol on fibrinolytic parameters in mild and moderate hypertensive patients. Can J Cardiol 2007; 23: 651-5. [CrossRef]

28. Erdem Y, Usalan C, Haznedaroğlu IC, Altun B, Arıcı M, Yaşavul U, et al. Effects of angiotensin converting enzyme and angiotensin II receptor inhibition on impaired fibrinolysis in systemic hypertension. Am J Hypertens 1999; 12: 1071-6. [CrossRef]

29. Remkova A, Kratochvil'ova H, Durina J. Impact of the therapy by renin-angiotensin system targeting antihypertensive agents perindopril versus telmisartan on prothrombotic state in essential hypertension. J Hum Hypertens 2008; 22: 338-45. [CrossRef]

30. Goodfriend TL, Elliott ME, Catt KJ. Angiotensin receptors and their antagonists. N Engl J Med 1996; 334: 1649-54. [CrossRef]

31. Warnholtz A, Nickenig G, Schulz E, Macharzina R, Brasen JH, Skatchkov $\mathrm{M}$, et al. Increased NADH-oxidase-mediated superoxide production in the early stages of atherosclerosis: evidence for involvement of the renin-angiotensin system. Circulation 1999; 99: 2027-33. [CrossRef]

32. Gomes A, Costa D, Lima JL, Fernandes E. Antioxidant activity of beta-blockers: an effect mediated by scavenging reactive oxygen and nitrogen species? Bioorg Med Chem 2006; 14: 4568-77. [CrossRef] 